\title{
New trend in colorectal cancer in Germany: are young patients at increased risk for advanced colorectal cancer?
}

\author{
Peter C. Ambe*, Stefan Jansen and Hubert Zirngibl
}

\begin{abstract}
Background: The role of colonoscopy in the screening of colorectal cancer (CRC) has been unequivocally established. In Germany, screening colonoscopy with full insurance reimbursement is available for individuals aged 55 and above, and/or for persons with well-known risk factors for CRC. However, advanced CRC is not uncommon in individuals below 55 years. This study was designed to investigate the incidence of advanced CRC in patients $<55$ years.

Methods: A retrospective analysis of data from a prospectively maintained CRC database of a university hospital in Germany was performed. Using the recommended age for screening colonoscopy as cutoff, the study population was divided into two groups: $<55$ years (study group) and $\geq 55$ years (control group). Both groups were compared with regard to the extent of CRC using the UICC stages. Only surgically managed patients were included for analysis. Advanced CRC was defined as UICC stage III or IV.

Results: Complete follow-up data was available for 609 patients treated between 2009 and 2013. The study group included 83 patients, 42 females and 41 males with a median age of $48.0 \pm 10$ years, while the control group was made up of 526 patients, 230 females and 296 males with a median age of $75.5 \pm 8.3$ years. Both groups were comparable with regard to gender distribution, $p=0.24$. Significantly more patients from the study group were diagnosed with advanced CRC in comparison to the control group, 56.6 vs. $43.9 \%, p=0.03$. There was no statistically significant difference amongst both groups with respect to cancer-related mortality, 10.8 vs. $12.5 \%, p=0.66$.

Conclusion: Patients below the recommended age for screening colonoscopy might be at increased risk for advanced CRC. There is need to decrease the recommended age for screening colonoscopy to prevent CRC or enable an early diagnosis in patients below 55 years.
\end{abstract}

Keywords: Colorectal cancer, Young age, Screening colonoscopy, Overall survival, CME, TME

\section{Background}

Colorectal cancer (CRC) is one of the most common solid malignancies in western nations $[1,2]$. Generally, CRC arises from a sequence of events that have been described as adenoma-carcinoma sequence [3]. This sequence can be effectively disrupted via screening. Preventing the transformation from an adenoma to a carcinoma, therefore, must be considered a priority for screening. The currently recommended CRC screening tests can be divided into two groups $[2,4,5]$. The first group of tests depends primarily on the detection of

\footnotetext{
* Correspondence: peter.ambe@helios-kliniken.de Department of Surgery, Helios University Hospital Wuppertal, Witten-Herdecke University, Heusnerstr. 40, 42283 Wuppertal, Germany
}

cancer in stool including the guaiac-based fecal occult blood test (gFOBT), the fecal immunochemical tests (FIT) based on fecal occult blood tests (FOBTs), and test for exfoliated DNA in stool (sDNA) [6, 7]. The second group enables the visualization of cancer and precancerous lesions via endoscopic (colonoscopy, sigmoidoscopy, capsule endoscopy) or radiologic (computed tomography, colonography, and barium enema) examination [8-10].

In Germany, screening colonoscopy was introduced in October 2002 as an alternative to FOBT for the screening of individual aged 55 years and above. The cost of screening colonoscopy for this population is fully covered by the statutory health insurance (SHI) which is 
responsible for insurance coverage of about $90 \%$ of the German population [11]. Screening colonoscopy for asymptomatic patients $<55$ years, however, is not submitted to SHI reimbursement.

The available literature suggests an increase in the rate of CRC in young individuals without predisposition for CRC [12-15]. Our clinical experience suggests that a large portion of young individuals presents with large tumors and are diagnosed at an advanced stage. A tempting hypothesis is that this trend could be altered if the cost of screening colonoscopy in young individuals without predisposition to CRC were covered by the SHI. This study aimed at examining the clinicopathological characteristics and outcomes of CRC in patients below the recommended colonoscopy age.

\section{Methods}

An analysis of prospectively collected data from our institutional CRC database was performed. Following the diagnosis of CRC, a written consent was received from each patient or their legal representative for the use of their data and specimens for research purposes. Ethics approval was received from the Ethics Committee at the Witten-Herdecke University. Data of all consecutive patients diagnosed with CRC was prospectively put into this database by specially trained individuals and study nurses. The database is continuously updated with information on the current status of registered patients. The fullness and accuracy of data is periodically controlled by an external audit. The database contains documentation of all cases of CRC irrespective of treatment option (endoscopic, palliation, or curative).

In our department, radical oncologic resection is performed in all patients undergoing curative surgery for CRC. Radical resection is reflected by the extent of surgical dissection of mesenteric lympho-vascular pathways including total mesocolic excision (CME) for colon cancer and total mesorectal excision (TME) for rectal cancer as described elsewhere [16, 17]. All procedures were performed either by an experienced senior surgeon or by a fellow/junior surgeon under direct supervision by a senior surgeon. The final tumor stage was reported using both the AJCC TNM and the Union Internationale Contre le Cancer (UICC) staging systems following histopathology. Patient characteristics including sex, age, and diagnosis were registered. Tumor variables included postoperative AJCC TNM tumor stage (pT), nodal stage $(\mathrm{pN})$, and tumor location $[18,19]$.

Only patients undergoing elective curative surgery following colonoscopy and histopathological confirmation of CRC were included for analysis. Patients with multiple cancers were excluded from analysis. Patients with palliation procedures and cases with emergency procedures were excluded from the study.
To achieve our goal, the study population was divided into two groups using the age for recommended screening colonoscopy as cutoff. Thus, the study group included all patients $<55$ years (screening colonoscopy generally not recommended) while the control group was made up of patients $\geq 55$ years.

\section{Statistical analysis}

The data generated was analyzed using the Statistical Package for Social Sciences (SPSS) version 23 (IBM Corp., Armonk, NY, USA). Continuous variables were described using medians and interquartile ranges $( \pm)$ where necessary. The chi-square test was used to study the differences amongst both groups. Binary logistic regression analysis was used to calculate odds ratios (OR). The two-sided $p$ values were reported where necessary with the level of significance set at $p<0.05$. A 95\% confidence interval (CI) was employed for all analyses. Survival diagrams were generated using the Kaplan-Meier Curve. The primary outcome was overall survival.

\section{Results}

The study population consisted of 609 patients with CRC managed with radical surgery within a 5-year period from 2009 to 2013. Using the cutoff age for full insurance reimbursement for screening colonoscopy in Germany ( 55 years), the study population was divided into two age-dependent groups: $<55$ years (study group) and $\geq 55$ years (control group), Fig. 1 . The median age of the study group was $48.0 \pm 10$ years (range $36-54$ years) and $75.5 \pm 8.3$ years (range $55-87$ years) for the control group. The baseline and clinicopathological features of the study population are presented in Table 1. Both groups were comparable with regard to gender distribution.

The location of CRC was similar in both groups, Table 1. Advanced CRC (T3 and T4) were found significantly more often in the group $<55$ years compared to the

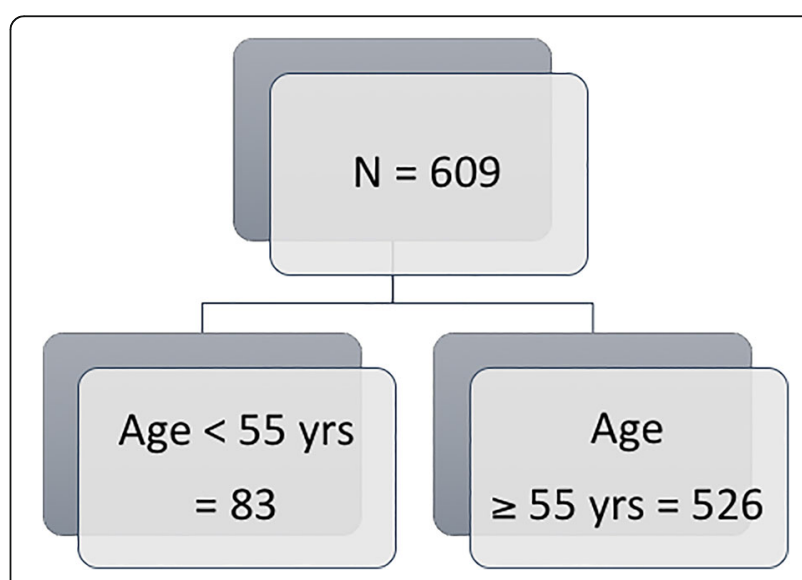

Fig. 1 Distribution of study population 
Table 1 Baseline and clinical characteristics of the study population

\begin{tabular}{|c|c|c|c|}
\hline Characteristics & Age $<55$ & Age $\geq 55$ & $P$ value \\
\hline N & 83 & 526 & / \\
\hline \multicolumn{4}{|l|}{ Sex } \\
\hline Female & $42(50.6 \%)$ & $230(43.7 \%)$ & \multirow[t]{2}{*}{0.24} \\
\hline Male & 41 (49.4\%) & $296(56.3 \%)$ & \\
\hline Mean age & $47.6 \pm 5.1$ years & $72.2 \pm 8.5$ years & / \\
\hline \multicolumn{4}{|l|}{ Location } \\
\hline Right colon & 19 (22.9\%) & $164(31.2 \%)$ & \multirow[t]{6}{*}{ / } \\
\hline Transverse & $5(5.0 \%)$ & 31 (5.9\%) & \\
\hline Left Colon & $23(27.7 \%)$ & $165(31.4 \%)$ & \\
\hline Upper rectum & $7(8.4 \%)$ & $40(7.6 \%)$ & \\
\hline Mid rectum & $12(14.5 \%)$ & $60(11.4 \%)$ & \\
\hline Lower rectum & 17 (20.5\%) & $66(12.5 \%)$ & \\
\hline \multicolumn{4}{|c|}{ AJCC tumor stage (pT) } \\
\hline 1 & $5(6.0 \%)$ & $83(15.8 \%)$ & \multirow[t]{4}{*}{0.023} \\
\hline 2 & $17(20.5 \%)$ & $96(18.3 \%)$ & \\
\hline 3 & $43(51.8 \%)$ & $266(50.5 \%)$ & \\
\hline 4 & $18(21.7 \%)$ & $81(15.4 \%)$ & \\
\hline \multicolumn{4}{|c|}{ AJCC nodal stage (pN) } \\
\hline 0 & $38(45.8 \%)$ & $319(60.7 \%)$ & \multirow[t]{3}{*}{0.03} \\
\hline 1 & $30(36.1 \%)$ & $120(22.8 \%)$ & \\
\hline 2 & $15(18.1 \%)$ & 87 (16.5\%) & \\
\hline \multicolumn{4}{|l|}{ UICC } \\
\hline । & $11(13.3 \%)$ & $147(28.0 \%)$ & \multirow[t]{4}{*}{0.03} \\
\hline$\|$ & $25(30.1 \%)$ & $148(28.1 \%)$ & \\
\hline III & $23(27.7 \%)$ & $129(24.5 \%)$ & \\
\hline IV & $24(28.9 \%)$ & $102(19.4 \%)$ & \\
\hline
\end{tabular}

control group, 73.4 vs. $65.9 \%, p=0.023$. Nodal involvement was recorded in $54.2 \%$ of cases in the group < 55 years compared to $39.3 \%$ of cases in the control group. This difference was statistically significant, $p=0.03$. Similarly, advanced CRC defined as stage III (27.7 vs. $24.5 \%)$ and IV (28.9 vs. 19.4\%) per UICC staging criteria was seen significantly more often in the younger group compared to the control group, $p=0.03$.

The median overall survival was $46.0 \pm 33.0$ months (range 19-73 months) in the group < 55 years and $31.0 \pm 27.0$ years (range 10-82 months) in the control group, Fig. 2. This difference was not statistically significant, $p=0.61$. Patients in the group $<55$ years had a higher odd for advanced CRC (OR 1.67 (1.045-2.66), CI: $95 \%, p=0.034)$. Nine cases $(10.8 \%)$ of cancer-related death were recorded in the group $<55$ years while 66 cancer-related (12.5\%) deaths were recorded in the control group within the time examined. The cumulative survival in this study is presented in Fig. 3. There was no statistically significant difference in the rate of cancerrelated death amongst both groups, $p=0.61$.

\section{Discussion}

Colorectal cancer is the second most common cause of cancer-related death in developed nations. The incidence of CRC has been shown to increase with age [20,21]. Screening colonoscopy might detect colorectal polyps in asymptomatic individuals which are usually removed thereby disrupting the adenoma-carcinoma-sequences $[5,22]$. Besides, screening colonoscopy in asymptomatic individuals also enables the diagnosis of CRC in an early stage for which curative resection is possible. Although the current German guidelines recommend screening for CRC in asymptomatic individuals beginning at the age of 50 years, full insurance reimbursement for screening colonoscopy is only offered to average-risk individuals aged $\geq 55$ years [11]. Our clinical experience suggests that a sizeable portion of young patients ( $<55$ years) presenting with $\mathrm{CRC}$ is diagnosed with advanced tumors. We hypothesized that this trend could be changed if full reimbursement for screening colonoscopy were accessible for individuals $<55$ years. This study examined the clinicopathological findings and outcomes of CRC in young patients $<55$ years.

Prospectively collected data for a continuously updated colorectal database at the Helios University Hospital in Wuppertal, Germany, was retrospectively analyzed. Six hundred and nine surgically managed cases of CRC including 83 patients aged $<55$ years were analyzed. Advanced local tumors pT3/T4 and nodal involvement $(\mathrm{pN}+)$ were seen significantly more often in patients $<55$ years compared to the control group. The median overall survival was longer in the group with young patients in comparison to the control group. Equally, the rate of cancer-related mortality was lower in the group with young patients compared to the control group. However, there was no statistically significant difference amongst both groups with regard to cumulative survival.

Although screening for CRC is generally recommended in asymptomatic average-risk individuals starting at the age of 50 years, the screening options vary widely [22]. Amongst all screening options, colonoscopy has been proven to be most effective. Besides being a screening tool, colonoscopy is useful for the diagnosis of CRC by providing biopsies for histopathology. Furthermore, colonoscopy plays a key role in the prevention of CRC by disrupting the adenoma-carcinoma-sequence via removal of colorectal polyps. However, the risk of CRC has been thought to be low in asymptomatic individual $<55$ years without hereditary predisposition. More so, the risk of colonoscopy-associated complications in this 


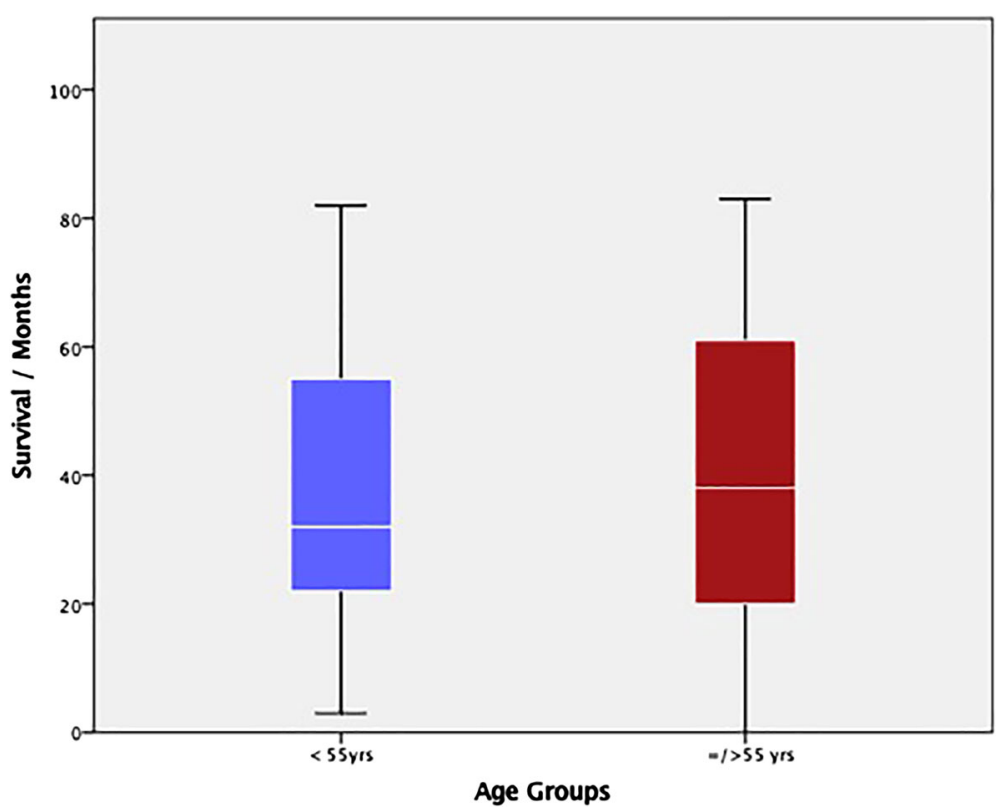

Fig. 2 Median survival in both groups

subpopulation is thought to overweigh its benefit [14]. Thus, colonoscopy is not generally recommended for screening young asymptomatic individuals at averagerisk for CRC.

Current literature suggests a $3.4 \%$ decrease in CRC incidence and a $3.0 \%$ reduction in the rate of CRC-related mortality from 2003 to 2007 in patients $>50$ years in the USA [23]. This trend has been attributed to increased screening, improvement of risk factors, and improved treatment of CRC [24]. In contrast to older individuals, the incidence of CRC in young adults with an average risk for CRC has been rising [12-15]. This trend must be blamed on the failure to detect and remove precancerous lesions in young adults due to lack of screening.

In Germany, colonoscopy has been established as the standard method of screening for CRC [25]. However, full insurance reimbursement for screening colonoscopy for individuals with an average risk for CRC is only



Fig. 3 Kaplan Meier Curve showing the cumulative survival 
possible at the age of 55 years and above. The costs for screening colonoscopy for average-risk individuals below this age limit are not reimbursed. Since there is a clear sequence of transformation from polyp (adenoma) to $\mathrm{CRC}$, it appears logical that CRC in young individuals could be preventable or early detected, if the costs for screening colonoscopy in this subgroup were to be reimbursed by the SHI.

In the present study, advanced CRC was found significantly more often in young adults below the recommended colonoscopy age compared to controls. This is not surprising since these patients underwent colonoscopy because of abdominal symptoms secondary to advanced CRC. Similar results have been published previously [26-29].

CRC at a young age ( $<50$ years) should prompt the search for inherited high-risk CRC syndromes such as familial adenomatous polyposis (FAP), Lynch syndrome (LS), MUTYH-associated polyposis (MAP), etc. However, inherited syndromes have been seen in a minority of cases, and merely about 10\% of CRC in young individuals has been attributed to hereditary conditions [14, 30-33]. The significance of identifying a hereditary syndrome as the cause of CRC must be the subsequent screening and genetic counseling of the patient's family with the aim of identifying carriers of the defective gene in order to ensure a strict screening and eventually enable an individualized syndrome-dependent management concept. An interesting finding in our study was the age of presentation. The median age of presentation was 48 years. Unfortunately, screening for hereditary syndromes was not systematically performed in these patients at that time. This practice has changed, and all patients with CRC now undergo genetic screening for hereditary CRC-associated syndromes.

Despite the presence of advanced CRC at the time of diagnosis, the median survival was better in the young group compared to the control. This finding might be secondary to the absence of concomitant medical conditions in the young group. Besides, this survival trend might be a result of improved surgical and oncologic management. More so, the better survival advantage seen in younger patients has been attributed to a more aggressive adjuvant chemotherapy in young patients due to the assumption that early onset of CRC is a poor prognostic factor [34].

Some limitations of this study need to be addressed. First, the retrospective design must be seen as a limitation to this study. Genetic assessment to investigate a possible association with hereditary syndromes was not systematically performed and therefore could not be analyzed. This is a major limitation in light of the median age (48 years) of the study population. Second, data on the use of other screening options especially
FOBT was not available. Although this screening option is not very reliable, it still plays an important role as an initial screening tool for CRC. Third, while the patients in the young group underwent colonoscopy due to symptoms, data on the portion of patients who underwent colonoscopy in the control group due to symptoms was not available and therefore could not be analyzed. Fourth, the effect of adjuvant chemotherapy was not analyzed. Finally, both groups were not matched with regard to BMI, smoking habits, and other sedentary lifestyles that might influence the development of CRC. Thus, there is a need for more investigation with better design and protocol.

Despite the above limitations, the results of this study confirm that young patients below the recommended colonoscopy screening age of 55 years in Germany are at increased risk for advanced CRC. This observation is in accordance with the result of a recently published population-based study from the Surveillance Epidemiology and End Results (SEER) database in the USA by Abdelsattar et al. [35].

Taken together, the results of this study are in line with available literature with regard to an increasing incidence of CRC in patients below the recommended screening age. Due to lack of screening, CRC is usually diagnosed in such cases at an advanced stage. This trend must be interpreted as an argument to re-think the starting age for CRC screening. Lowering the age limit for SHI reimbursement for screening colonoscopy in Germany might enable the prevention or early detection of CRC in young patients.

\section{Conclusion}

The incidence of CRC in young patients at average-risk for CRC is increasing. In Germany, screening colonoscopy is not reimbursed for asymptomatic individuals at average-risk for CRC below the age of 55 years. For such individuals, colonoscopy is usually performed due to symptoms and CRC is frequently diagnosed in an advanced stage. Lowering the age limit for insurance reimbursement for screening colonoscopy in Germany might enable the prevention or an early detection of CRC in young patients.

\section{Abbreviation \\ AJCC: American Joint Committee of Cancer; CRC: Colorectal cancer; FAP: Familial adenomatous polyposis; FIT: Fecal immunochemical tests; gFOBT: Guaiac-based fecal occult blood test; LS: Lynch syndrome; MAP: MUTYH-associated polyposis; SEER: Surveillance Epidemiology and End Results; UICC: Union Internationale Contre le Cancer}

\section{Acknowledgements}

Many thanks to all the colleagues of the CRC database for their continued dedication and hard work

Funding

None. 


\section{Availability of data and materials}

The dataset supporting the conclusions of this article is included within the article and its additional files.

\section{Authors' contributions}

PA contributed to the design of the study. PA and SJ contributed to the data collection. PA and SJ contributed to the analysis and interpretation of the study. PA drafted the manuscript. PA, SJ, and HZ critically reviewed and accepted the final version of the manuscript.

\section{Ethics approval and consent to participate}

A written consent was received from all patients or their legal representatives for the use of their data and specimens for research purposes. Ethics approval was received from the Ethics Committee of the Witten-Herdecke University (Approval Nr.05/2015).

\section{Competing interests}

The authors declare that they have no competing interests.

\section{Congress presentation}

Poster presentation at the annual surgical congress in Nordrhein Westfalia, Herne 2016.

\section{Publisher's Note}

Springer Nature remains neutral with regard to jurisdictional claims in published maps and institutional affiliations.

Received: 19 May 2017 Accepted: 13 August 2017

Published online: 23 August 2017

\section{References}

1. Siegel R, Naishadham D, Jemal A. Cancer statistics, 2013. CA Cancer J Clin. 2013;63(1):11-30.

2. Smith RA, Brooks D, Cokkinides V, Saslow D, Brawley OW. Cancer screening in the United States, 2013: a review of current American Cancer Society guidelines, current issues in cancer screening, and new guidance on cervical cancer screening and lung cancer screening. CA Cancer J Clin. 2013; 63(2):88-105.

3. Leslie A, Carey FA, Pratt NR, Steele RJ. The colorectal adenoma-carcinoma sequence. Br J Surg. 2002;89(7):845-60.

4. Smith RA, Andrews K, Brooks D, DeSantis CE, Fedewa SA, Lortet-Tieulent J, Manassaram-Baptiste D, Brawley OW, Wender RC. Cancer screening in the United States, 2016: a review of current American Cancer Society guidelines and current issues in cancer screening. CA Cancer J Clin. 2016;66(2):96-114.

5. Force UPST. Screening for colorectal cancer: recommendation and rationale. Ann Intern Med. 2002;137(2):129.

6. Barton MK. Fecal occult blood testing remains a valuable screening tool. CA Cancer J Clin. 2014;64(1):3-4

7. Bresalier RS, Kopetz S, Brenner DE. Blood-based tests for colorectal cancer screening: do they threaten the survival of the FIT test? Dig Dis Sci. 2015; 60(3):664-71.

8. Lieberman DA, Weiss DG, Bond JH, Ahnen DJ, Garewal H, Chejfec G. Use of colonoscopy to screen asymptomatic adults for colorectal cancer. Veterans affairs cooperative study group 380. N Engl J Med. 2000;343(3):162-8.

9. Quintero E, Castells A, Bujanda L, Cubiella J, Salas D, Lanas Á, Andreu M, Carballo F, Morillas JD, Hernández C. Colonoscopy versus fecal immunochemical testing in colorectal-cancer screening. N Engl J Med. 2012;366(8):697-706

10. Shapiro JA, Klabunde CN, Thompson TD, Nadel MR, Seeff LC, White A Patterns of colorectal cancer test use, including $C T$ colonography, in the 2010 National Health Interview Survey. Cancer Epidemiol Biomark Prev. 2012;21(6):895-904.

11. Brenner H, Altenhofen L, Stock C, Hoffmeister M. Prevention, early detection, and overdiagnosis of colorectal cancer within 10 years of screening colonoscopy in Germany. Clin Gastroenterol Hepatol. 2015;13(4):717-23.

12. Deen Kl, Silva H, Deen R, Chandrasinghe PC. Colorectal cancer in the young, many questions, few answers. World Journal Of Gastrointestinal Oncology. 2016;8(6):481-8.

13. Gado A, Ebeid B, Abdelmohsen A, Axon A. Colorectal cancer in Egypt is commoner in young people: is this cause for alarm? Alexandria Journal of Medicine. 2014;50:197-201.
14. Inra JA, Syngal S. Colorectal cancer in young adults. Dig Dis Sci. 2015;60(3):722-33.

15. Rossana R, Luis T, Eloy FR, Raúl M, Luis C, Paola M. Colorectal cancer in the young: clinicopathologic features and prognostic factors from a cancer institute in Peru / Cáncer colorrectal en los jóvenes: factores pronósticos y características clínico patológicas en un instituto del cáncer de Perú. Rev Gastroenterol Peru. 2016;1:35

16. Heald RJ, Moran BJ, Ryall RD, Sexton R, MacFarlane JK. Rectal cancer: the Basingstoke experience of total mesorectal excision, 1978-1997. Arch Surg. 1998;133(8):894-9.

17. Hohenberger W, Weber K, Matzel K, Papadopoulos T, Merkel S. Standardized surgery for colonic cancer: complete mesocolic excision and central ligation-technical notes and outcome. Color Dis. 2009;11(4):354-64. discussion 364-355

18. Frederick L, Page DL, Fleming ID, Fritz AG, Balch CM, Haller DG, Morrow M. AJCC cancer staging manual, vol. 1. Berlin: Springer Science \& Business Media; 2002.

19. Hari DM, Leung AM, Lee JH, Sim MS, Vuong B, Chiu CG, Bilchik AJ. AJCC cancer staging manual 7th edition criteria for colon cancer: do the complex modifications improve prognostic assessment? J Am Coll Surg. 2013:217(2):181-90

20. Jiang Z, Wang X, Tan X, Fan Z: Effect of age on survival outcome in operated and non-operated patients with colon cancer: a population-based study. PLoS One 2016, 11(1):1.

21. Pestana JSG, Martins SFF: Original article: colorectal cancer: comparative analysis of clinical and pathological characteristics in patients aged above and below 45 years of age and impact on prognosis. Câncer colorretal: análise comparativa das características clínicas e anatomopatológicas em doentes com idade superior e inferior a 45 anos de idade e impacto no prognóstico (Portuguese) 2016

22. Force USPST. Screening for colorectal cancer: U.S. preventive services task force recommendation statement. Ann Intern Med. 2008;149(9):627-37.

23. Levin B, Lieberman DA, McFarland B, Smith RA, Brooks D, Andrews KS, Dash C, Giardiello FM, Glick S, Levin TR, et al. Screening and surveillance for the early detection of colorectal cancer and adenomatous polyps, 2008: a joint guideline from the American Cancer Society, the US multi-society task force on colorectal cancer, and the American College of Radiology. CA Cancer J Clin. 2008;58(3):130-60.

24. Edwards BK, Ward E, Kohler BA, Eheman C, Zauber AG, Anderson RN, Jemal A, Schymura MJ, Lansdorp-Vogelaar I, Seeff LC, et al. Annual report to the nation on the status of cancer, 1975-2006, featuring colorectal cancer trends and impact of interventions (risk factors, screening, and treatment) to reduce future rates. Cancer. 2010;116(3):544-73.

25. Brenner H, Hoffmeister M, Brenner G, Altenhofen L, Haug U. Expected reduction of colorectal cancer incidence within 8 years after introduction of the German screening colonoscopy programme: estimates based on 1,875,708 screening colonoscopies. Eur J Cancer. 2009;45(11):2027-33.

26. Saluja SS, Manipadam JM, Mishra PK, Sachdeva S, Solanki N, Shah H. Young onset colorectal cancer: how does it differ from its older counterpart? Indian J Cancer. 2014;51(4):565.

27. Scott RB, Rangel LE, Osler TM, Hyman NH. Clinical science: rectal cancer in patients under the age of 50 years: the delayed diagnosis. Am J Surg. 2016:211:1014-8.

28. Sousa J, Souza C, Fernandes M, Castro Durães L, Almeida R, Santos A, Silva E, Oliveira P. Do young patients have different clinical presentation of colorectal cancer causing delay in diagnosis? Int J Color Dis. 2014;29(4):519.

29. Teng A, Lee DY, Cai J, Patel SS, Bilchik AJ, Goldfarb MR. Patterns and outcomes of colorectal cancer in adolescents and young adults. J Surg Res. 2016;205:19-27.

30. Limburg PJ, Harmsen WS, Chen HH, Gallinger S, Haile RW, Baron JA, Casey G, Woods MO, Thibodeau SN, Lindor NM. Original article-alimentary tract: prevalence of alterations in DNA mismatch repair genes in patients with young-onset colorectal cancer. Clin Gastroenterol Hepatol. 2011;9:497-502.

31. Mork ME, You YN, Ying J, Bannon SA, Lynch PM, Rodriguez-Bigas MA, Vilar E. High prevalence of hereditary cancer syndromes in adolescents and young adults with colorectal cancer. J Clin Oncol Off J Am Soc Clin Oncol. 2015; 33(31):3544-9.

32. Gómez-Fernández N, Castellví-Bel S, Fernández-Rozadilla C, Balaguer F, Muñoz J, Madrigal I, Milà M, Graña B, Vega A, Castells A. Molecular analysis of the APC and MUTYH genes in Galician and Catalonian FAP families: a different spectrum of mutations? BMC Med Genet. 2009;10(1):1. 
33. Lynch H, Lynch P, Lanspa S, Snyder C, Lynch J, Boland C. Review of the lynch syndrome: history, molecular genetics, screening, differential diagnosis, and medicolegal ramifications. Clin Genet. 2009;76(1):1-18.

34. Quah HM, Joseph R, Schrag D, Shia J, Guillem JG, Paty PB, Temple LK, Wong WD, Weiser MR. Young age influences treatment but not outcome of colon cancer. Ann Surg Oncol. 2007;14(10):2759-65.

35. Abdelsattar ZM, Wong SL, Regenbogen SE, Jomaa DM, Hardiman KM, Hendren S. Colorectal cancer outcomes and treatment patterns in patients too young for average-risk screening. Cancer. 2016;122(6):929-34.

Submit your next manuscript to BioMed Central and we will help you at every step:

- We accept pre-submission inquiries

- Our selector tool helps you to find the most relevant journal

- We provide round the clock customer support

- Convenient online submission

- Thorough peer review

- Inclusion in PubMed and all major indexing services

- Maximum visibility for your research

Submit your manuscript at www.biomedcentral.com/submit 